\title{
lon species fractions in the far-field plume of a high-specific impulse Hall thruster
}

\author{
Richard R. Hofer* \\ QSS Group, Inc. \\ NASA Glenn Research Center \\ Cleveland, $\mathrm{OH} 44135$ USA \\ richard.hofer@grc.nasa.gov
}

\author{
Alec D. Gallimore ${ }^{\dagger}$ \\ Plasmadynamics and Electric Propulsion Laboratory \\ University of Michigan \\ Ann Arbor, MI 48109 USA
}

\begin{abstract}
An ExB probe was used to measure the ion species fractions of $\mathrm{Xe}^{+}, \mathrm{Xe}^{2+}$, and $\mathrm{Xe}^{3+}$ in the farfield plume of the NASA-173Mv2 laboratory-model Hall thruster. The thruster was operated at a constant xenon flow rate of $10 \mathrm{mg} / \mathrm{s}$ and discharge voltages of 300-900 V. The ExB probe was placed two meters downstream of the thruster exit plane on the thruster centerline. At a discharge voltage of $300 \mathrm{~V}$, the species fractions of $\mathrm{Xe}^{2+}$ and $\mathrm{Xe}^{3+}$ were lower, but still consistent with, previous Hall thruster studies using other mass analyzers. Over discharge voltages of $300-900 \mathrm{~V}$, the $\mathrm{Xe}^{2+}$ species fractions increased from 0.04 to 0.12 and the $\mathrm{Xe}^{3+}$ species fraction increased from 0.01 to 0.02 .
\end{abstract}

\section{INTRODUCTION}

As used for spacecraft applications in Earth orbit such as station-keeping, orbit-raising, and orbit-transfers, the xenon Hall thruster is most often regarded as a 1600 second specific impulse device operating at discharge voltages of $300 \mathrm{~V}$. Mission studies have shown though that increases in the specific impulse of Hall thrusters to 2000-3000 seconds can enhance or enable a number of Earth-orbital and interplanetary missions. ${ }^{1-4}$

The NASA-173M series of laboratorymodel Hall thrusters were conceived in order to understand the design challenges and physical mechanisms determining performance at highspecific impulse (2000-3000 seconds). ${ }^{5-9}$ The basic design philosophy was that changes to the magnetic field topography would be required for efficient operation above 1600 seconds specific impulse. Advanced magnetic circuits allowing for in situ variation of the magnetic field topography were therefore incorporated into each thruster. The NASA-173Mv1, built jointly by the University of Michigan and the NASA Glenn Research Center (GRC), first established the validity of this approach. ${ }^{5-6}$ In a performance study at low current density, changes to the magnetic field topography at high-specific impulse were shown to be critical to achieving efficient operation. $^{6}$ The follow-on version, the GRCdeveloped NASA-173Mv2, incorporated design improvements suggested by its predecessor. A performance mapping of the NASA-173Mv2 at several current densities established that efficient operation at high-specific impulse was possible if a minimum current density was maintained and the magnetic field topography was properly shaped.

Design and experiment have established that Hall thrusters can operate efficiently at highspecific impulse. A need still exists though to improve understanding of the relationship between the thruster design and the microscopic plasma properties. This is necessary to further increase performance, evaluate and improve lifetime, and enable integration with spacecraft. To those ends, a series of plasma diagnostics have been used with the NASA-173Mv2 to better understand the plasma characteristics. $^{7-9}$

In the present work, an ExB probe was used to measure the variation of the ion species fractions with discharge voltage in the NASA-173Mv2 Hall thruster. An ExB probe is a plasma diagnostic that selectively filters charged particles according to their velocities. ${ }^{10-21}$ Because multiply-charged ions in Hall thrusters will have velocities proportional to the square root of their

\footnotetext{
* Research Engineer, Member AIAA

$\dagger$ Associate Professor, Associate Fellow AIAA
} 
charge-state $\left(\mathrm{q}^{1 / 2}\right),{ }^{22}$ an $\mathrm{ExB}$ probe can discriminate between distinct ion species. Examination of the relative height of the ion current peaks from the probe can then be used to compute the species fractions.

Measurements of the species fractions are important because multiply-charged ions affect thruster performance and the lifetime of the thruster and sensitive spacecraft surfaces (e.g., solar arrays and optics). At constant beam current, the presence of multiply-charged ions increases specific impulse while decreasing thrust and efficiency. ${ }^{22}$ Increased erosion by multiplycharged ions (due to their increased energy) can also decrease the lifetime of the thruster and spacecraft surfaces. At high discharge voltages, the importance of multiply-charged ions on Hall thruster performance and lifetime is relatively unknown because measurements have thus far been limited to $300-500 \mathrm{~V}$ in xenon Hall thrusters. ${ }^{19,21,23-26}$

\section{EXPERIMENTAL APPARATUS}

The thruster hardware and configuration were the same as the experiments reported in Ref. 7. This included the thruster, power electronics, vacuum facility, and the thruster mounting scheme in the vacuum facility. In the experiments reported here, an ExB probe was added two meters downstream of the thruster exit plane on the thruster centerline.

\section{A. NASA-173Mv2 Hall effect thruster}

The NASA-173Mv2 is a $5 \mathrm{~kW}$-class laboratory-model Hall thruster that has a discharge chamber outer diameter of $173 \mathrm{~mm}$ (Figure 1; see Ref. 7 for a detailed description). A fixed structure of magnetic poles pieces, an inner coil (IC) and an outer coil (OC) are used to form the primary magnetic circuit. Fine control of the magnetic field is provided with an internal trim coil (ITC) and an external trim coil (ETC). In the data presented in this paper, only the inner and outer coils were used. The results of experiments including the effects of the internal and external trim coils on ion species fractions have not yet been analyzed.

Figure 2 shows the total specific impulse and total efficiency of the NASA-173Mv2 at $10 \mathrm{mg} / \mathrm{s}$ versus discharge voltage. ${ }^{7}$ The specific impulse and efficiency include the cathode flow and the efficiency also includes the power to the magnets. Specific impulse and efficiency range from 1600-3400 seconds and 51-61\%, respectively, over voltages of 300-1000 V.

The plasma discharge was powered by a matching pair of commercially available power supplies wired in series that provided a $1200 \mathrm{~V}$, 16 A output. The discharge filter consisted of a $100 \mu \mathrm{F}$ capacitor in parallel with the supply outputs. Other commercially available power supplies were used to power the magnet coils and the cathode heater and keeper. The laboratorymodel hollow cathode was a GRC design capable of emission currents up to $20 \mathrm{~A}$. As shown in Figure 1, the cathode was positioned above the thruster.

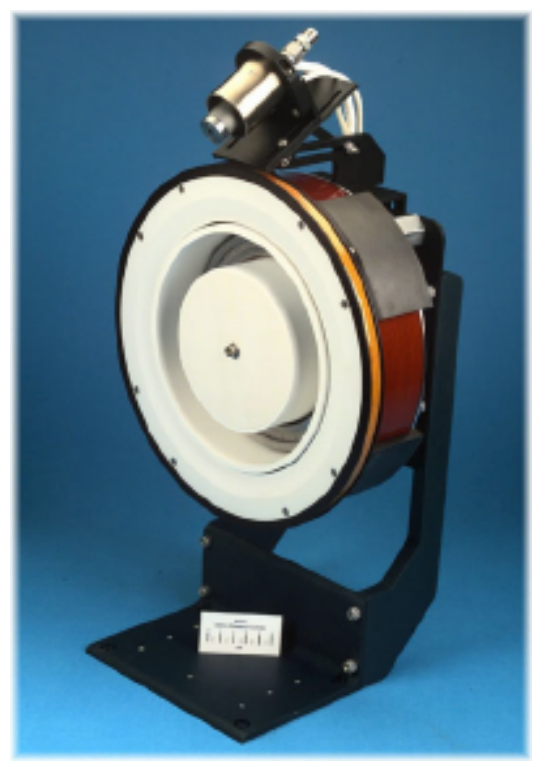

Figure 1 - Photograph of the NASA-173Mv2 Hall thruster.

High-purity xenon was supplied through stainless steel feed lines with 20 and $200 \mathrm{sccm}$ mass flow controllers. The controllers were calibrated before the experiments using a constantvolume method. Based on the calibrations, the uncertainty was estimated as $\pm 0.9 \%$ for the anode flow rate and $\pm 1.1 \%$ for the cathode flow rate.

Thruster telemetry was acquired using a 22-bit datalogger. The DC accuracy of the unit, as reported by the manufacturer, is $0.004 \%$. However, calibration of each channel using digital multimeters increased the uncertainty to $\pm 0.05 \%$ for voltage and $\pm 0.2 \%$ for current. 
The thruster was operated for four hours after initial exposure to vacuum conditions to allow for outgassing of the chamber walls. Upon subsequent thruster shutdowns and restarts or a change in the discharge voltage, the thruster was operated for at least 30-60 minutes before data was acquired. This procedure allowed enough time for the discharge current to reach a steady-state value.
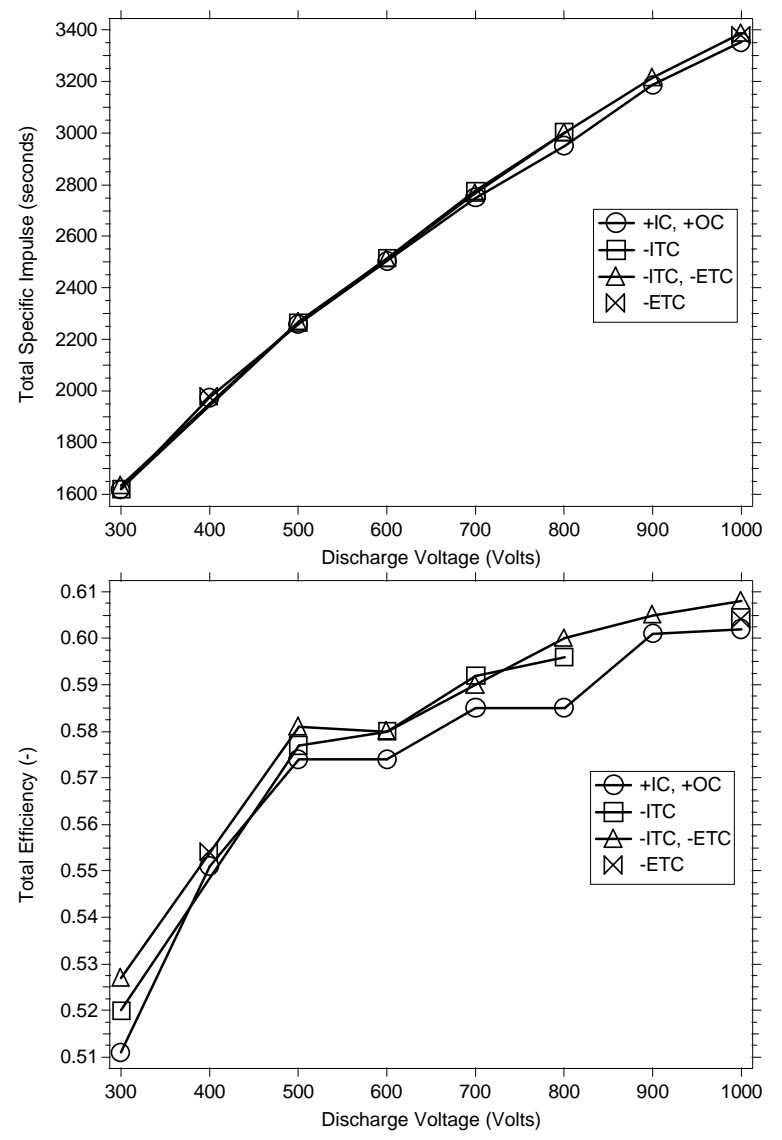

Figure 2 - Total specific impulse and efficiency versus discharge voltage of the NASA-173Mv2 at 10 mg/s. (from Ref. 7)

\section{B. Vacuum facility}

The experiments were conducted in vacuum facility 12 (VF12) at GRC. VF12 is a cylindrical, stainless steel chamber $3.0 \mathrm{~m}$ in diameter by $9.6 \mathrm{~m}$ in length. The facility is cryogenically pumped and backed by a turbomolecular pump for removal of gases not pumped by the cryosurfaces. The thruster was mounted on the thrust stand described in Ref. 7. The thrust stand pendulum was locked down and not used for these experiments. In this position, the thruster was near the chamber's vertical centerline and fired $8.9 \mathrm{~m}$ down the length of the tank toward the pumps, which are located along the back half of the chamber. A hot-cathode ionization gauge was mounted $0.4 \mathrm{~m}$ below the vertical chamber centerline, $5.2 \mathrm{~m}$ downstream of the thruster. Pressure measurements were corrected for xenon using the base pressure on air and a correction factor of 2.87 for xenon. For a total xenon flow rate of $11 \mathrm{mg} / \mathrm{s}$, the pressure was $4.6 \times 10^{-6}$ Torr, after correcting for xenon and the base pressure on air, which was $1.0 \times 10^{-7}$ Torr. This test pressure corresponded to a xenon pumping speed of 340,000 1/s.

\section{ExB probe (Wien filter)}

\section{Theory of operation}

The classical dynamics of a beam of charged particles in electric and magnetic fields are governed by the Lorentz force equation,

$$
\vec{F}=q e(\vec{E}+\vec{u} \times \vec{B})
$$

(where the symbols have their usual meaning). The ExB probe, also known as a Wien filter, selects particles with a particular velocity by balancing the electric and magnetic fields such that there is no net force acting on those particles. ${ }^{10-21}$

$$
0=q e(\vec{E}+\vec{u} \times \vec{B})
$$

If the ExB probe is constructed with the electric and magnetic field perpendicular to each other and the particle velocity,

$$
\begin{aligned}
\vec{E} & =(0, E, 0) \\
\vec{B} & =(0,0, B) \\
\vec{u} & =(u, 0,0)
\end{aligned}
$$

then Equation 2 becomes,

$$
u=-\frac{E}{B}
$$

Equation 4 shows that the particle velocity can be chosen by adjusting the electric and magnetic fields. In practice, a constant magnetic field is usually applied with permanent magnets. The electric field is usually established between two parallel plates separated by a gap, d, that are biased to a potential, $\mathrm{V}_{\text {probe, }}$, such that 


$$
E=-\frac{V_{\text {probe }}}{d}
$$

Then the velocity pass condition in an ExB probe is,

$$
u=\frac{V_{\text {probe }}}{B d}
$$

Particles that satisfy Equation 6 pass through the ExB field region and reach a collection electrode where they are recorded as current. The resulting current-voltage characteristic is therefore related to the velocity distribution function. It is important to note that an ExB probe is a velocity selector because the charge-state and mass of the ions do not appear in Equation 4. Thus, an ExB probe will not detect signatures due to chargeexchange collisions but will detect elastic collisions through signal broadening.

In a Hall thruster, particles are accelerated electrostatically to a velocity given by, ${ }^{22}$

$$
u_{i}=\sqrt{\frac{2 q_{i} e V_{a, i}}{m_{x e}}}
$$

where the subscript, $i$, indicates the charge of the ion $(\mathrm{i}=1,2,3, \ldots), \mathrm{V}_{\mathrm{a}, \mathrm{i}}$ is the effective accelerating potential, and $\mathrm{m}_{\mathrm{xe}}$ is the mass of a xenon atom. Substituting Equation 7 into Equation 6 and solving for the plate voltage yields an expression in terms of the effective accelerating potential of each ion species and charge-state (i.e., the ion energy),

$$
V_{p r o b e, i}=\sqrt{\frac{2 q_{i} e V_{a, i}}{m_{x e}}}(B d)
$$

The accelerating potential that each charge-state experiences in Hall thrusters differs only by a few tens of volts. ${ }^{19,21}$ Thus, the charge-states will roughly appear in an ExB current-voltage characteristic at multiples of $\mathrm{q}^{1 / 2}$ above the singlycharged peak.

\section{Design and experimental setup}

The ExB probe was based on previous designs used to study ion thrusters. ${ }^{20}$ Kim's ExB probe, which was the first to be used on a Hall thruster, was also based on these designs. ${ }^{19,21}$ Shown schematically in Figure 3, the probe used in these experiments consisted of three main sections: the entrance collimator, ExB test section, and exit collimator. The entrance collimator was $127 \mathrm{~mm}$ in length and had two circular orifices at either end that were 0.5 and $1.0 \mathrm{~mm}$ in diameter. In the $127 \mathrm{~mm}$ long test section, the magnetic field was applied with permanent magnets that provided a magnetic field strength at the test section center of $0.16 \mathrm{~T}$. The electric field was established with a pair of aluminum plates machined from channel stock. The bias plates were separated by a distance of $\mathrm{d}=42.5 \mathrm{~mm}$ with legs used to minimize electric field fringing that were $\mathrm{d} / 4$ in length. ${ }^{14,17}$ The exit collimator was $127 \mathrm{~mm}$ long and had an exit orifice diameter of $3.2 \mathrm{~mm}$. A $23 \mathrm{~mm}$ diameter tungsten collection electrode was placed at the end of the exit collimator. The entrance and exit collimator orifices were aligned using a laser. The acceptance angle of the probe was $0.7^{\circ}$. Probe resolution was conservatively estimated as $7 \%$ of the ion energy. ${ }^{19}$

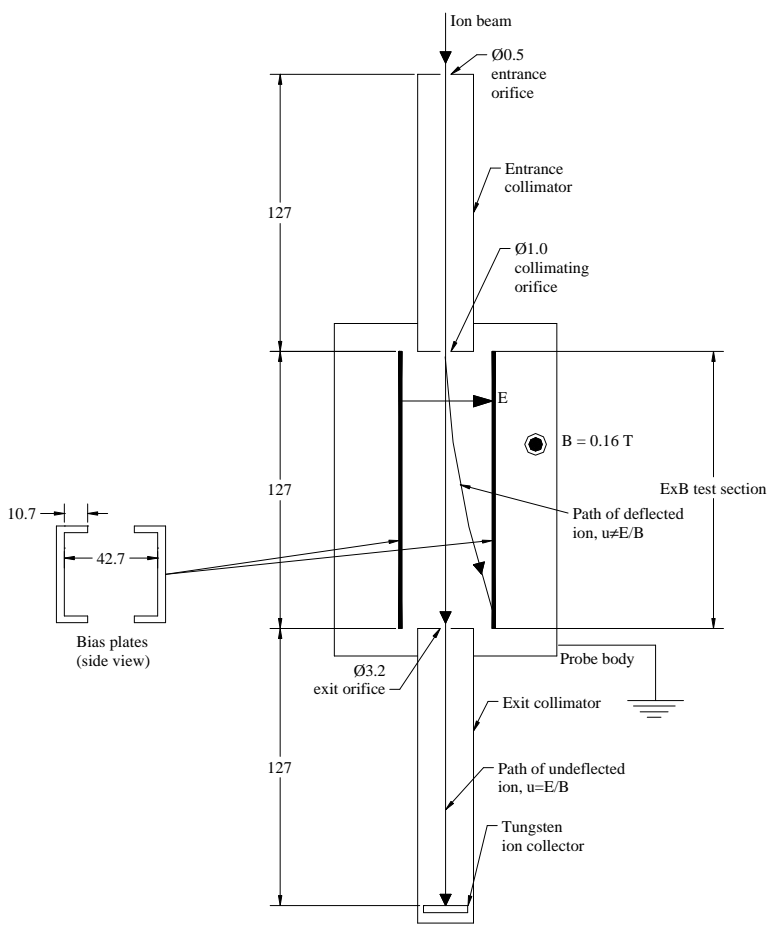

Figure 3 - Schematic of the ExB probe. Dimensions are given in millimeters.

The entrance orifice of the probe was placed two meters downstream of the thruster exit plane and on the thruster centerline, within an accuracy of $\pm 0.5 \mathrm{~cm}$ in both the axial and radial directions. The entrance and exit collimators were 
aligned perpendicular to the thruster exit plane with a laser to an accuracy of $\pm 0.5^{\circ}$.

Figure 4 shows the electrical schematic of the ExB probe. The plate bias was applied with a commercially available power supply and was swept over a range of voltages in two volt steps. For a given thruster operation condition, each voltage sweep was repeated 3-5 times and then averaged together to reduce measurement uncertainty. The supply outputs were biased with respect to ground using a pair of $1 \mathrm{M} \Omega$ resistors so that the potential at the mid-point of the plates was held near facility ground. Current from the collection electrode was measured with a picoammeter through $50 \mathrm{Ohm}$, shielded coaxial cable. Except for the bias plates and the collection electrode, the entire probe was grounded to the vacuum facility.

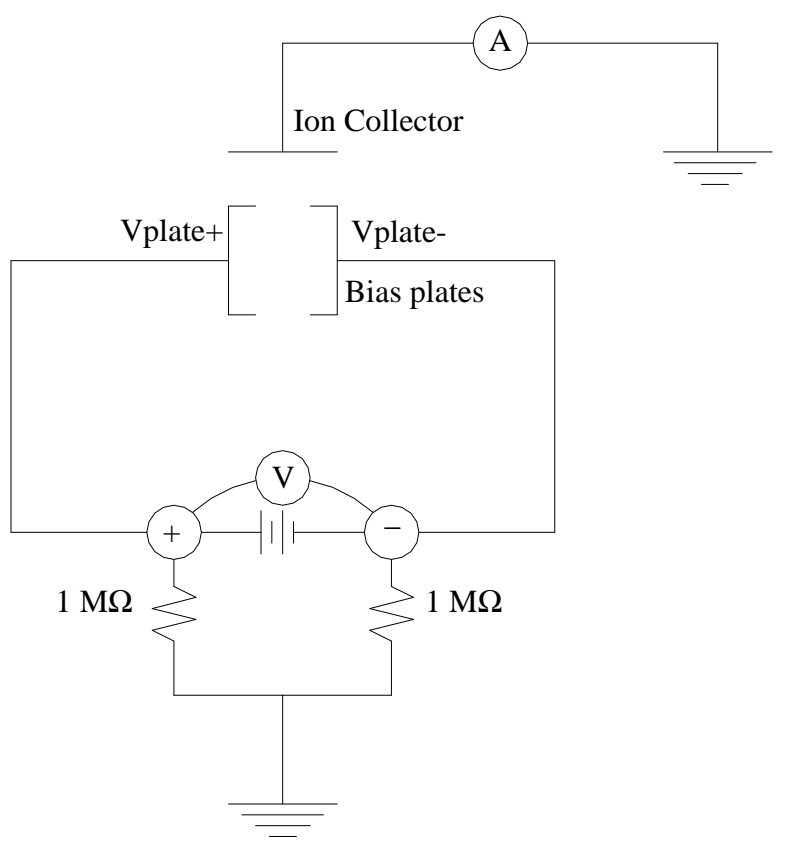

Figure 4 - Electrical schematic of the ExB probe.

\section{Data analysis}

Since the goal of the experiments was to obtain the ion species fractions as a function of the discharge voltage, data analysis consisted of interpreting the peak heights measured by the ExB probe. The $\mathrm{Xe}^{+}$and $\mathrm{Xe}^{2+}$ peaks were easily identified for all operating conditions. Signal broadening due to elastic collisions and probe resolution limitations resulted in the $\mathrm{Xe}^{2+}$ and $\mathrm{Xe}^{3+}$ signals overlapping at discharge voltages of 500-
$800 \mathrm{~V}$. In those cases, the $\mathrm{Xe}^{3+}$ ion current was taken where the first derivative of the ion current crossed, or nearly crossed, zero. The voltage where this occurred always closely corresponded to $3^{1 / 2} * \mathrm{~V}_{\text {probe, } 1}$. Some discharge voltages showed evidence of $\mathrm{Xe}^{4+}$, but the signal never represented a significant fraction of the total signal. For example, if the signal at $900 \mathrm{~V}$ (where $\mathrm{Xe}^{4+}$ was most evident, see Figure 7 in section III) were included in the species fractions calculations, then the $\mathrm{Xe}^{4+}$ fraction would have been 0.001 . Because the signal was so small, $\mathrm{Xe}^{4+}$ was not included in the calculations.

Using the peak heights to calculate the species fractions was equivalent to approximating the ion energy distribution function as a monoenergetic beam. In a Hall thruster, the beam has a distribution with a finite width of energies, since ions are produced along the length of the discharge chamber at different accelerating potentials. $\mathrm{Kim}^{19,21}$ accounted for these effects by including a model of the ion energy distribution function and found reasonable agreement with other mass analyzers. ${ }^{23-26}$ While modeling the distribution is a more rigorous approach that should reduce uncertainty, it requires that probeinduced signal broadening is much less than collisional broadening. The ExB probe used in these experiments had an energy resolution of $7 \%$ (compared to $1 \%$ with Kim's probe), which was too high to neglect probe broadening. As a result, it was concluded that modeling the distribution would introduce more uncertainty to the calculations than using the peak heights. While using the peak heights introduces additional uncertainty, the computed species fractions were still comparable to other mass analyzers (see section III below). A conservative estimate of the uncertainty that included the effects of using the peaks heights is discussed in section II.C.4.

The ion current of each species from the probe traces was expressed as,

$$
I_{i}=e q_{i} n_{i} u_{i} A_{c}\left(1+\gamma_{i}\right)
$$

where $A_{c}$ was the current collection area, $\gamma_{i}$ was the secondary electron emission yield (given in electrons per ion), and $\mathrm{n}_{\mathrm{i}}$ was the number density.

The secondary electron emission yield was taken from data in Ref. 27 for xenon bombardment on tungsten which showed that $\gamma_{i}$ 
was on average $0.018,0.216$, and 0.756 for $\mathrm{Xe}^{+}$, $\mathrm{Xe}^{2+}$, and $\mathrm{Xe}^{3+}$, respectively, over the range of ion energies in these experiments.

From the ion currents, the current fractions were computed as,

$$
\Omega_{i}=\frac{I_{i}}{\sum I_{i}} \quad i=1,2,3
$$

where,

$$
\sum \Omega_{i}=1
$$

The ion species fractions were given by,

$$
\zeta_{i}=\frac{n_{i}}{\sum n_{i}} \quad i=1,2,3
$$

where,

$$
\sum \zeta_{i}=1
$$

Equations 7, 9, and 12 were then substituted into Equation 10 to obtain an expression relating the current and species fractions,

$$
\Omega_{i}=\frac{q_{i}^{3 / 2} \zeta_{i}\left(1+\gamma_{i}\right)}{\sum\left(q_{i}^{3 / 2 \zeta} \zeta_{i}\left(1+\gamma_{i}\right)\right)}
$$

where it was assumed that the collection area and effective acceleration potential of each species were the same. Solving the system of equations defined by Equations 13 and 14 yielded the ion species fractions.

\section{Measurement uncertainty}

To estimate the measurement uncertainty, the sensitivity of each ion species fraction was analyzed by considering: the uncertainty in the probe voltage and current identified for each species, probe misalignment and resolution, the variation in accelerating potential with ion species, and whether the secondary electron emission yield was included. Based on this analysis, the uncertainty in the species fractions was estimated to be $\pm 0.02, \pm 0.01$, and \pm 0.005 for $\mathrm{Xe}^{+}, \mathrm{Xe}^{2+}$, and $\mathrm{Xe}^{3+}$, respectively. Other sources of error, such as the loss of particles over the two meter path length and the effects of using the peak heights to identify the species current fractions, were not included. Methods to estimate the added uncertainty of these effects are currently being considered. However, preliminary estimates did show that the additional uncertainty was on the order of the uncertainty from all other sources. As a result, the uncertainty was revised to the more conservative estimate of $\pm 0.04, \pm 0.02$, and \pm 0.01 for $\mathrm{Xe}^{+}, \mathrm{Xe}^{2+}$, and $\mathrm{Xe}^{3+}$, respectively. At $300 \mathrm{~V}$, this equated to a percentage uncertainty of $\pm 4 \%$, $\pm 50 \%$ and $\pm 100 \%$ for $\mathrm{Xe}^{+}, \mathrm{Xe}^{2+}$, and $\mathrm{Xe}^{3+}$, respectively.

\section{RESULTS AND DISCUSSION}

ExB probe measurements were taken with the thruster operating at an anode flow rate of 10.0 $\mathrm{mg} / \mathrm{s}$ and a cathode flow rate of $1.0 \mathrm{mg} / \mathrm{s}$. The discharge voltage was varied from 300-900 V. The ExB probe was two meters downstream of the thruster exit plane on the thruster centerline. At each discharge voltage, the effects of the magnetic field were evaluated by using several combinations of the coils. In this paper, data with the inner and outer coils are presented. The results of experiments including the effects of the internal and external trim coils have not yet been analyzed. Thruster telemetry from the test series are in the appendix as Table 1.

Figures 5-7 are representative ExB probe traces at 300,600, and $900 \mathrm{~V}$, respectively. Each figure is the average of three to five voltage sweeps of the ExB probe. In general, the probe traces yielded distinct and repeatable spectra for the $\mathrm{Xe}^{+}, \mathrm{Xe}^{2+}$, and $\mathrm{Xe}^{3+}$ peaks. The $\mathrm{Xe}^{2+}$ and $\mathrm{Xe}^{3+}$ peaks closely corresponded to the expected $q^{1 / 2}$ dependence.

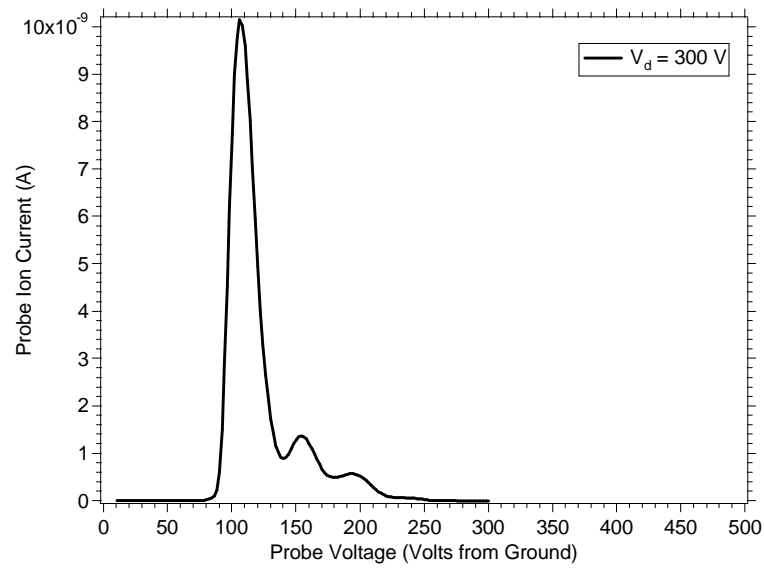

Figure 5 - ExB probe ion current versus probe voltage at $300 \mathrm{~V}$. 


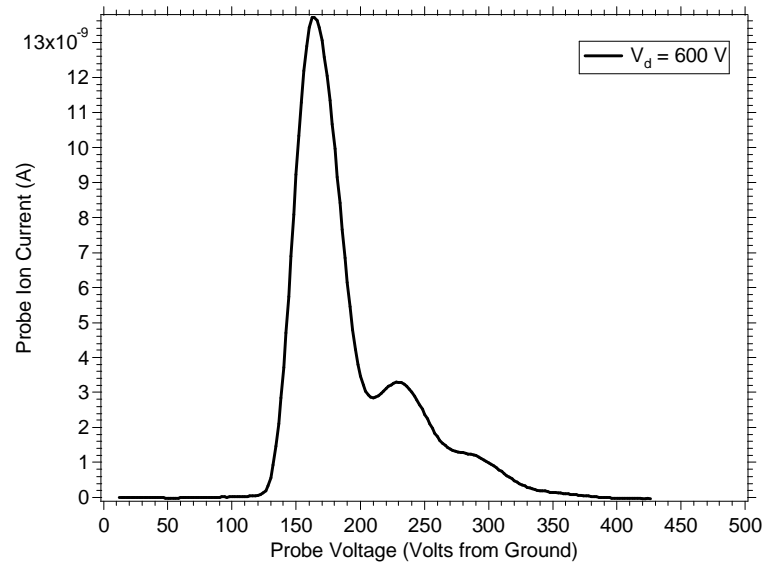

Figure 6 - ExB probe ion current versus probe voltage at $600 \mathrm{~V}$.

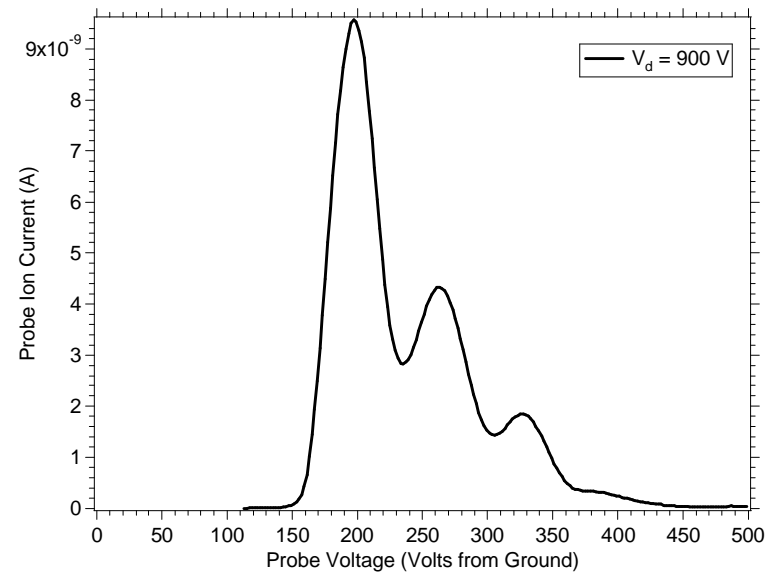

Figure 7 - ExB probe ion current versus probe voltage at $900 \mathrm{~V}$.

The widths of the probe spectra for each species show a clear broadening with discharge voltage. This result correlated with measurements of the ion voltage distribution that showed the same trend. ${ }^{8}$ The implications of these results on thruster operation are discussed further in Ref. 8.

The variation of the ion species fractions with discharge voltage is shown in Figure 8 and tabulated in the appendix as Table 2. While the results indicated a general increase in the fraction of multiply-charged ions with increasing discharge voltage, $\mathrm{Xe}^{+}$still dominated the plasma at all discharge voltages. Over the range of 300-900 V, the species fraction of $\mathrm{Xe}^{+}$decreased from 0.95 to 0.86. Over the same voltage range, the $\mathrm{Xe}^{2+}$ species fractions increased from 0.04 to 0.12 and the $\mathrm{Xe}^{3+}$ species fraction increased from 0.01 to 0.02 . At $300 \mathrm{~V}$, the fractions of $\mathrm{Xe}^{2+}$ and $\mathrm{Xe}^{3+}$ measured by the ExB probe were lower, but still consistent with, previous Hall thruster studies using other mass analyzers. ${ }^{19,21,23-26}$ These past studies have shown the plume to be composed of $0.06-0.11 \mathrm{Xe}^{2+}$ and $0.01 \mathrm{Xe}^{3+}$.

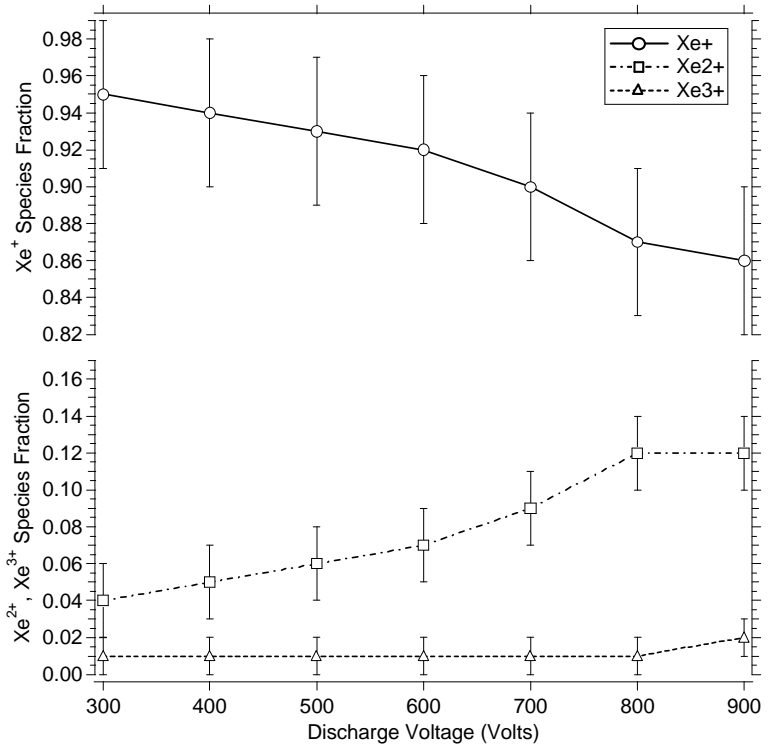

Figure 8 - Ion species fractions versus discharge voltage.

Multiply-charged ions reduce the thruster efficiency because,

$$
\frac{\eta}{\eta^{+}}=\frac{\left(\sum^{\Omega_{\mathrm{i}, \text { beam }}} / \sqrt{q_{i}}\right)^{2}}{\sum^{\Omega_{\mathrm{i}, \text { beam }}} / q_{i}}
$$

where $\eta^{+}$is the efficiency of a singly-charged plasma and $\Omega_{\mathrm{i} \text {,beam }}$ are the beam current fractions. Note that the beam current fractions are different than the probe current fractions defined in Equation 14 because of the effects of secondary electron emission on the collected ion current. The right hand side of Equation 15 is always less than one, so the efficiency of a multiply-charged plasma (for the same beam current), is always less than that of a singly-charged plasma. Applying Equation 15 to the measured species fractions showed that the thruster efficiency decreased by 1$3 \%$ over 300-900 $\mathrm{V}$ due to the presence of multiply-charged ion species. While this is a small decrease in efficiency, Equation 15 does not include the extra energy losses of producing multiply-charged ions, thermal losses due to ion acceleration into the discharge chamber walls, and the angular distribution of multiply-charged ions 
(measurements from thruster centerline usually show higher fractions of multiply-charged species). ${ }^{19,21,23-26}$ These effects, as well as the effects of multiply-charged ions on thruster lifetime, are currently being considered in further detail.

\section{ACKNOWLEDGEMENTS}

Program support for this research through

Code $\mathrm{R}$ Energetics funding is gratefully acknowledged.

\section{REFERENCES}

1. Noca, M., Brophy, J. R., "Over Powering Solar System Exploration," AIAA-1997-2914, $33^{\text {rd }}$ Joint Propulsion Conference, Seattle, WA, July 6-9, 1997.

2. Oleson, S. R., "Advanced Electric Propulsion for Space Solar Power Satellites," AIAA1999-2872, 35 ${ }^{\text {th }}$ Joint Propulsion Conference, Los Angeles, CA, June 20-24, 1999.

3. Oleson, S. R., "Mission Advantages of Constant Power, Variable Isp Electrostatic Thrusters," AIAA-2000-3413, 36 ${ }^{\text {th }}$ Joint Propulsion Conference, Huntsville, AL, July 17-19, 2000.

4. Fiehler, D. I., Oleson, S. R., "A Comparison of Electric Propulsion Systems for Mars Exploration," AIAA-2003-4574, 39 ${ }^{\text {th }}$ Joint Propulsion Conference, Huntsville, AL July 20-23, 2003.

5. Hofer, R. R., Peterson, P. Y., Gallimore, A. D., "A High Specific Impulse Two-Stage Hall Thruster with Plasma Lens Focusing," IEPC01-036, $27^{\text {th }}$ International Electric Propulsion Conference, Pasadena, CA, Oct 14-19, 2001.

6. Hofer, R. R., Gallimore, A. D., "The Role of Magnetic Field Topography in Improving the Performance of High-Voltage Hall Thrusters," AIAA-2002-4111, $38^{\text {th }}$ Joint Propulsion Conference, Indianapolis, IN, July 7-10, 2002.

7. Hofer, R. R., Jankovsky, R. S., "The Influence of Current Density and Magnetic Field Topography in Optimizing the Performance, Divergence, and Plasma Oscillations of High Specific Impulse Hall Thrusters," IEPC-03142, $28^{\text {th }}$ International Electric Propulsion Conference, Toulouse, France, March 17-21, 2003.
8. Hofer, R. R., Gallimore, A. D., "Recent Results from Internal and Very-Near-Field Plasma Diagnostics of a High Specific Impulse Hall Thruster," IEPC-03-037, $28^{\text {th }}$ International Electric Propulsion Conference, Toulouse, France, March 17-21, 2003.

9. Hofer, R. R., Gallimore, A. D., "Ion voltage diagnostics in the far-field plume of a highspecific impulse Hall thruster," AIAA-20034556, $39^{\text {th }}$ Joint Propulsion Conference, Huntsville, AL July 20-23, 2003.

10. Seliger, R. L., "ExB Mass-Separator Design," Journal of Applied Physics, Vol. 43, No. 5, May 1972.

11. Vahrenkamp, R. P., "Measurement of Double Charged Ions in the Beam of a 30-cm Mercury Bombardment Thruster," AIAA-73-1057, AIAA $10^{\text {th }}$ Electric Propulsion Conference, Lake Tahoe, NV, Oct 31 - Nov 2, 1973.

12. Quiros, E. L., "Some Experimental Facts that Indicate the Elimination of Astigmatism in Ion Beams with Separators Using Crossed Electric and Magnetic Fields," Journal of Applied Physics, Vol. 52, No. 3, March 1981.

13. Batson, P. E., "High-energy resolution electron spectrometer for 1-nm spatial analysis," Review of Scientific Instruments, Vol. 57, No. 1, Jan 1986.

14. Leal-Quiros, E., Prelas, M. A., "New TiltedPoles Wien Filter with Enhanced Performance," Review of Scientific Instruments, Vol. 60, No. 3, March 1989.

15. Leal-Quiros, E., Prelas, M. A., "Focused High-Intensity Proton Beam from a Lithium Source by Using an ExB Stigmatic Selector," Review of Scientific Instruments, Vol. 61, No. 1, Jan 1990.

16. Guan, S., Marshal, A. G., "A Mass- and Velocity-Broadband Ion Deflector for OffAxis Ion Injection Into a Cyclotron Resonance Ion Trap," Review of Scientific Instruments, Vol. 67, No. 2, Feb 1996.

17. Anderson, J. R, Fitzgerald, D., "Fullerene Propellant Research for Electric Propulsion," AIAA-96-3211, 1996.

18. Wrenger, B., Meiwes-Broer, K. H., "The Application of a Wien Filter to Mass Analysis of Heavy Clusters from a Pulsed Supersonic Nozzle Source," Review of Scientific Instruments, Vol. 68, No. 5, May 1997. 
19. Kim, S. W., "Experimental Investigations of Plasma Parameters and Species-Dependent Ion Energy Distribution in the Plasma Exhaust Plume of a Hall Thruster," Ph.D. Dissertation, University of Michigan, 1999.

20. Williams, G. J., Domonkos, M. T., Chavez, J. M., "Measurement of Doubly Charged Ions in Ion Thruster Plumes," IEPC-2001-310, $27^{\text {th }}$ International Electric Propulsion Conference, Pasadena, CA, Oct 14-19, 2001.

21. Kim, S. W., "Plume Study of a 1.35-kW SPT100 Using an ExB Probe," Journal of Spacecraft and Rockets, Vol. 39, No. 6, NovDec 2002.

22. Hofer, R. R., Jankovsky, R.S., "A Hall Thruster Performance Model Incorporating the Effects of a Multiply-Charged Plasma," AIAA-2001-3322, $37^{\text {th }}$ Joint Propulsion Conference, Salt Lake City, UT, July 8-11, 2001.

23. King, L.B., "Transport-property and Mass Spectral Measurements in the Plasma Exhaust Plume of a Hall-effect Space Propulsion System," Ph.D. Dissertation, University of Michigan, 1998.

24. Gulczinski, F.S., "Examination of the Structure and Evolution of Ion Energy Properties of a $5 \mathrm{~kW}$ Class Laboratory Hall Effect Thruster at Various Operational Conditions," Ph.D. Dissertation, University of Michigan, 1999.

25. King, L. B., Gallimore, A. D., "Mass Spectral Measurements in the Plume of an SPT-100 Hall Thruster," Journal of Propulsion and Power, Vol. 16, No. 6, Nov-Dec 2000.

26. Gulczinski, F. S., Gallimore, A.D., "NearField Ion Energy and Species Measurements of a 5-kW Hall Thruster," Journal of Propulsion and Power, Vol. 17, No. 2, MarApr 2001.

27. Hagstrum, H. D., "Auger Ejection of Electrons from Tungsten by Noble Gas Ion," Physical Review, Vol. 96, No. 2., pp. 325-335, 1954. 


\section{APPENDIX}

Table 1 - NASA-173Mv2 telemetry from the ExB probe measurements.

\begin{tabular}{|c|c|c|c|c|c|c|c|c|c|c|}
\hline Point & $\mathrm{Vd}(\mathrm{V})$ & Id (A) & Anode $(\mathrm{mg} / \mathrm{s})$ & $\begin{array}{c}\text { Cathode } \\
(\mathrm{mg} / \mathrm{s})\end{array}$ & $\begin{array}{l}\text { Inner Coil } \\
\text { (A) }\end{array}$ & $\begin{array}{l}\text { Outer Coil } \\
\text { (A) }\end{array}$ & $\begin{array}{c}\text { Internal Trim } \\
\text { Coil (A) }\end{array}$ & $\begin{array}{c}\text { External Trim } \\
\text { Coil (A) }\end{array}$ & $\operatorname{Vcg}(\mathrm{V})$ & $\begin{array}{c}\text { Pressure } \\
\text { (Torr) }\end{array}$ \\
\hline 93 & 300.4 & 8.87 & 10.00 & 1.00 & 1.75 & 1.50 & 0.00 & 0.00 & -11.8 & $4.6 \mathrm{E}-06$ \\
\hline 101 & 400.4 & 9.24 & 10.00 & 1.00 & 2.50 & 2.26 & 0.00 & 0.00 & -13.0 & $4.6 \mathrm{E}-06$ \\
\hline 105 & 500.4 & 9.37 & 10.00 & 1.00 & 3.00 & 2.20 & 0.00 & 0.00 & -13.3 & $4.6 \mathrm{E}-06$ \\
\hline 109 & 600.2 & 9.53 & 10.00 & 1.00 & 3.26 & 2.49 & 0.00 & 0.00 & -13.4 & $4.6 \mathrm{E}-06$ \\
\hline 113 & 700.4 & 9.71 & 10.00 & 1.00 & 3.41 & 3.06 & 0.00 & 0.00 & -14.0 & $4.6 \mathrm{E}-06$ \\
\hline 117 & 800.1 & 9.81 & 10.00 & 1.00 & 3.82 & 3.30 & 0.00 & 0.00 & -14.1 & $4.6 \mathrm{E}-06$ \\
\hline 126 & 800.1 & 9.84 & 10.00 & 1.00 & 3.85 & 3.61 & 0.00 & 0.00 & -13.8 & $4.6 \mathrm{E}-06$ \\
\hline
\end{tabular}

Table 2 - Ion species fractions on centerline, two meters downstream of the NASA-173Mv2 at $10 \mathrm{mg} / \mathrm{s}$.

\begin{tabular}{|c|c|c|c|}
\hline \multirow{2}{*}{$\mathrm{Vd}$} & \multicolumn{3}{|c|}{ Species Fraction } \\
\cline { 2 - 4 } & $\mathrm{Xe}+$ & $\mathrm{Xe}+$ & $\mathrm{Xe}+$ \\
\hline 300 & 0.95 & 0.04 & 0.01 \\
\hline 400 & 0.94 & 0.05 & 0.01 \\
\hline 500 & 0.93 & 0.06 & 0.01 \\
\hline 600 & 0.92 & 0.07 & 0.01 \\
\hline 700 & 0.90 & 0.09 & 0.01 \\
\hline 800 & 0.87 & 0.12 & 0.01 \\
\hline 900 & 0.86 & 0.12 & 0.02 \\
\hline
\end{tabular}

